Review began 09/07/2021 Review ended 09/28/2021 Published 09/30/2021

\section{(๑) Copyright 2021}

Sandhu et al. This is an open access article distributed under the terms of the Creative Commons Attribution License CC-BY 4.0., which permits unrestricted use, distribution, and reproduction in any medium, provided the original author and source are credited.

\title{
Telemedicine Versus In-Person Visits in Postoperative Care in Orthopedic Patients: Follow-Up Study From North India
}

\author{
Kuldip S. Sandhu ${ }^{1}$, Akashdeep Singh ${ }^{1}$, Akashdeep Singh ${ }^{1}$, Daljinder Singh ${ }^{1}$, Annie Sandhu ${ }^{2}$ \\ 1. Orthopedics, Government Medical College, Patiala, IND 2. Emergency Department, All India Institute of Medical \\ Sciences, Rishikesh, IND
}

Corresponding author: Daljinder Singh , kd27sand@gmail.com

\begin{abstract}
Background: Telemedicine is improving healthcare delivery in orthopedic patients but the data regarding this are scarce from India, especially North India.

Methodology: During this one-year prospective observational study, all patients with fractures of the upper end of tibia requiring surgical intervention and who consented to avail teleconsultation services were included. All these patients were assessed by patient satisfaction score pre-operatively. Patients were randomly assigned for post-operative care schedules of 5 and 14 days in telemedicine and inpatient visits during their follow-up period.
\end{abstract}

Results: A total of 50 patients were included and the satisfaction rating among the two groups was identical. The average patient satisfaction score (on a 10-point scale) was found to be 9.77 in the inpatient visits based on the one-on-one follow-up group and 9.79 in the telemedicine consultation group.

Conclusion: In orthopedics, the implementation of telemedicine can minimize the need for the patient to physically visit the outpatient department. The rates of response and overall patient satisfaction were high in the telemedicine group. However, more efforts should be made to address the limitations and problems of using telemedicine.

Categories: Orthopedics

Keywords: follow up, orthopedic patients, postoperative care, teleconsultation, telemedicine

\section{Introduction}

Over the past several years, multiple forms of telemedicine have enabled healthcare personnel to improve healthcare delivery at a distance by monitoring post-operative follow-ups and interpret diagnostic imaging. The western world is using telemedicine facilities more often than countries like India. Although owning to the coronavirus disease 2019 (COVID-19) pandemic, the healthcare system has been disrupted globally.

Therefore, in March 2020, Indian authorities (National Medical Council) formulated guidelines for the appropriate use of telemedicine by registered medical practitioners and surgical and medical specialists to reduce disruption in healthcare and prevent the further spread of COVID-19 [1]. The utilization of telemedicine technologies will be advantageous both for the patients as well as healthcare providers. This provides better treatment outcomes in orthopedic settings as it is a multifaceted surgical specialty [1,2]. To counter COVID-19 spread, many institutions in China and the United States reportedly increased their use of telemedicine in surgical specialties, and have recently issued recommendations for its execution in treating appropriate patients. However, due to the pandemic, it is difficult to gather sufficient feedback regarding patient and provider satisfaction with telemedicine. Moreover, in Indian literature, the data regarding the use of telemedicine in orthopedic practice are scarce; therefore, the present study was designed with a goal to compare post-operative patient satisfaction while using telemedicine and in-person hospital visits of patients during the COVID-19 period [3,4].

\section{Materials And Methods}

\section{Study design}

The present one-year (May 2020 to April 2021) prospective observational study was conducted in the Department of Orthopedics, Government Medical College and Hospital, Patiala, Punjab, India. The study has been approved by the Government Medical College, Patiala with the registration number TRG.9(310)202035217.

\section{Patient selection}




\section{Cureus}

All the patients who presented with fractures of the upper end of the tibia and requiring surgical intervention were evaluated. After an extensive preoperative evaluation (which included routine investigations like COVID-19 reverse transcription-polymerase chain reaction [RT-PCR], blood counts, biochemical investigations, and radiological tests), patients who consented to the study were included.

Inclusion criteria include patients with fresh fractures of the upper end of the tibia and age between 18 and 60 years.

Exclusion criteria used were patients with pathological fractures, fractures with impending compartment syndrome, compound fractures, and comminuted fractures, patients with co-morbid conditions (hypertension, diabetes mellitus, and chronic liver/kidney/cardiopulmonary disease), patients less than 18 years and above 60 years, and patients who did not consent to enrollment in the study.

Pre-operatively, all these patients were assessed by patient satisfaction score. Further, the patients were randomly assigned for post-operative care schedules of 5 and 14 days in telemedicine and inpatient visits during their follow-up period. Telemedicine patients used their gadgets like computers or mobile devices through telemedicine programs.

\section{Outcome measurement}

Both the groups were evaluated using validated pain scores and patient satisfaction scores.

Telemedicine consultations were given to the patients as per the national guidelines and were given without any charges during the study period. Patients who had telephonic consultations were asked to fill up a questionnaire a week after telephonic consultations. The pain scale of patients was measured with a numerical scale ranging from 0 to 10 , with 0 indicating no pain, 1 indicating mild pain, 4-6 indicating minor pain, and 7-10 indicating severe pain.

The satisfaction score was calculated using an 11-point ordinal scale with five anchoring points. Patients gave feedback using the following scores from 0 to 10: (0-1) this visit was not what I hoped; (2-4) it could be better in many ways; (5) visit was helpful; (6-8) exceptionally beneficial visit; and (9-10) one of the most beneficial visits [5].

\section{Results}

A total of 50 patients participated in the study with a majority $(80 \%)$ of male patients $(\mathrm{M}: \mathrm{F}$ ratio $=4: 1)$. Majority of the patients were in 46-60 years age group $(n=22 ; 44 \%)$ followed by $31-45$ years age group $(n=$ $21 ; 42 \%)$ and $18-30$ years age group $(n=7 ; 14 \%)$. Majority $(30 \%)$ of the patients had type 4 fracture followed by type 3 (20\%) and type 5 (20\%), and type 1 (4\%) being the least common type (Tables $1-3$ ).

\begin{tabular}{|c|c|c|c|c|c|c|}
\hline \multirow{3}{*}{ Sex } & \multicolumn{4}{|c|}{ Mode of follow-up } & \multirow{2}{*}{\multicolumn{2}{|c|}{ Total }} \\
\hline & \multicolumn{2}{|c|}{ OPD } & \multicolumn{2}{|c|}{ Telemedicine } & & \\
\hline & No. & $\%$ & No. & $\%$ & No. & $\%$ \\
\hline Female & 5 & $20 \%$ & 5 & $20 \%$ & 10 & $20 \%$ \\
\hline Male & 20 & $80 \%$ & 20 & $80 \%$ & 40 & $80 \%$ \\
\hline Total & 25 & $100 \%$ & 25 & $100 \%$ & 50 & $100 \%$ \\
\hline
\end{tabular}

\section{TABLE 1: Gender distribution of all patients}

OPD, outpatient department. 


\section{Cureus}

\begin{tabular}{|c|c|c|c|c|c|c|}
\hline \multirow{3}{*}{ Age group (years) } & \multicolumn{4}{|c|}{ Mode of follow-up } & \multirow{2}{*}{\multicolumn{2}{|c|}{ Total }} \\
\hline & \multicolumn{2}{|c|}{ OPD } & \multicolumn{2}{|c|}{ Telemedicine } & & \\
\hline & No. & $\%$ & No. & $\%$ & No. & $\%$ \\
\hline $18-30$ & 4 & $16 \%$ & 3 & $12 \%$ & 7 & $14 \%$ \\
\hline $31-45$ & 10 & $40 \%$ & 11 & $44 \%$ & 21 & $42 \%$ \\
\hline $46-60$ & 11 & $44 \%$ & 11 & $44 \%$ & 22 & $44 \%$ \\
\hline Total & 25 & $100 \%$ & 25 & $100 \%$ & 50 & $100 \%$ \\
\hline
\end{tabular}

\section{TABLE 2: Age distribution of all patients}

OPD, outpatient department.

\begin{tabular}{|c|c|c|c|c|c|c|}
\hline \multirow{3}{*}{ Fracture Tyре } & \multicolumn{4}{|c|}{ Mode of follow-up } & \multirow{2}{*}{\multicolumn{2}{|c|}{ Total }} \\
\hline & \multicolumn{2}{|c|}{ OPD } & \multicolumn{2}{|c|}{ Telemedicine } & & \\
\hline & No. & $\%$ & No. & $\%$ & No. & $\%$ \\
\hline Type 1 & 1 & $4 \%$ & 1 & $4 \%$ & 2 & $4 \%$ \\
\hline Type 2 & 4 & $16 \%$ & 4 & $16 \%$ & 8 & $16 \%$ \\
\hline Type 3 & 5 & $20 \%$ & 5 & $20 \%$ & 10 & $20 \%$ \\
\hline Type 4 & 7 & $28 \%$ & 8 & $32 \%$ & 15 & $30 \%$ \\
\hline Type 5 & 5 & $20 \%$ & 5 & $20 \%$ & 10 & $20 \%$ \\
\hline Type 6 & 3 & $12 \%$ & 2 & $8 \%$ & 5 & $10 \%$ \\
\hline Total & 25 & $100 \%$ & 25 & $100 \%$ & 50 & $100 \%$ \\
\hline
\end{tabular}

TABLE 3: Fracture classification of all patients

OPD, outpatient department.

During the immediate postoperative period, patient satisfaction was equivalent in both categories. In both these groups, the surgeon enquired about surgical findings, post-operative recovery duration, degree, and duration of pain, and physical examinations, which included motion range testing, any discharge from the operative site, fever, and redness around the wound. During telemedicine follow-up, the surgeons did not touch the knee physically but examined the patient virtually. The assessment of wound healing, discharge, and swelling was done using visual aid.

In this study, satisfaction ratings among the two groups were found to be identical. The average patient satisfaction score (on the scale of 0-10) was found to be 9.77 and 9.79 in the inpatient visit follow-up and telemedicine follow-up, respectively. During this study, some of the patients (about 15\%) have preferred other alternative types of follow-up. Analyzing pain scores showed similar improvement in both groups on the day of surgery and at follow-up (Tables 4, 5). 


\section{Cureus}

\begin{tabular}{|c|c|c|c|c|c|c|}
\hline \multirow{3}{*}{ Preoperative pain score } & \multicolumn{4}{|c|}{ Mode of follow-up } & \multirow{2}{*}{\multicolumn{2}{|c|}{ Total }} \\
\hline & \multicolumn{2}{|l|}{ OPD } & \multicolumn{2}{|c|}{ I elemedicine } & & \\
\hline & No. & $\%$ & No. & $\%$ & No. & $\%$ \\
\hline Mild & - & - & - & - & - & - \\
\hline Moderate & - & - & - & - & - & - \\
\hline Severe & 25 & $100 \%$ & 25 & $100 \%$ & 50 & $100 \%$ \\
\hline Total & 25 & $100 \%$ & 25 & $100 \%$ & 50 & $100 \%$ \\
\hline \multirow{3}{*}{ Preoperative satisfaction score } & \multicolumn{4}{|c|}{ Mode of follow-up } & \multirow{2}{*}{\multicolumn{2}{|c|}{ Total }} \\
\hline & \multicolumn{2}{|l|}{ OPD } & \multicolumn{2}{|c|}{ Telemedicine } & & \\
\hline & No. & $\%$ & No. & $\%$ & No. & $\%$ \\
\hline Satisfactory & - & - & - & - & - & - \\
\hline Dissatisfactory & - & - & - & - & - & - \\
\hline Neutral & - & - & - & - & - & - \\
\hline Satisfactory & - & - & - & - & - & - \\
\hline Very satisfactory & 25 & $100 \%$ & 25 & $100 \%$ & 50 & $100 \%$ \\
\hline Total & 25 & $100 \%$ & 25 & $100 \%$ & 50 & $100 \%$ \\
\hline
\end{tabular}

TABLE 4: Preoperative pain score and patient satisfaction score

OPD, outpatient department. 


\section{Cureus}

\begin{tabular}{|c|c|c|c|c|c|c|c|}
\hline \multirow{3}{*}{ Postoperative pain score } & \multicolumn{5}{|c|}{ Mode of follow-up } & \multirow{2}{*}{\multicolumn{2}{|c|}{ Total }} \\
\hline & \multicolumn{3}{|c|}{ OPD } & \multicolumn{2}{|c|}{ Telemedicine } & & \\
\hline & No. & \multicolumn{2}{|c|}{$\%$} & No. & $\%$ & No. & $\%$ \\
\hline Mild & 17 & \multicolumn{2}{|c|}{$68 \%$} & 16 & $64 \%$ & 33 & $66 \%$ \\
\hline Moderate & 8 & \multicolumn{2}{|c|}{$32 \%$} & 9 & $36 \%$ & 17 & $34 \%$ \\
\hline Severe & - & \multicolumn{2}{|c|}{ - } & - & - & - & - \\
\hline Total & 25 & \multicolumn{2}{|c|}{$100 \%$} & 25 & $100 \%$ & 50 & $100 \%$ \\
\hline \multirow{3}{*}{ Postoperative satisfaction score } & \multicolumn{5}{|c|}{ Mode of follow-up } & \multirow{2}{*}{\multicolumn{2}{|c|}{ Total }} \\
\hline & \multicolumn{2}{|c|}{ OPD } & \multicolumn{3}{|c|}{ Telemedicine } & & \\
\hline & No. & $\%$ & No. & & $\%$ & No. & $\%$ \\
\hline Very unsatisfied & - & - & - & & - & - & - \\
\hline Unsatisfied & - & - & - & & - & - & - \\
\hline Neutral & - & - & - & & - & - & - \\
\hline Satisfied & - & - & - & & - & - & - \\
\hline Very satisfied & 25 & $100 \%$ & 25 & & $100 \%$ & 50 & $100 \%$ \\
\hline Total & 25 & $100 \%$ & 25 & & $100 \%$ & 50 & $100 \%$ \\
\hline
\end{tabular}

\section{TABLE 5: Postoperative pain score and patient satisfaction score}

OPD, outpatient department.

There were low complication rates among these groups. Three patients in the outpatient department (OPD) follow-up had shown pain and swelling and two patients in telemedicine had shown pain and swelling. These findings of patients had shown doubt of possible blood clots or infection-related complications. All these patients were investigated on the same days with tests like blood parameters and Doppler ultrasound scans of concerned parts, which showed no significant evidence of venous thromboembolism or infection. Patients had been assessed for any missed or subsequent complications.

\section{Discussion}

Due to the emergence of COVID-19, the aim of the entire health system is to reduce and prevent the spread, morbidity, and mortality due to COVID-19. This has led to the diversion of medical resources, thus compromising on the routine outpatient department services and therefore limiting the routine medical care, especially by in-person visits. To encounter this major problem, many hospitals throughout the world opted for telemedicine services. Even in developing countries like India, the government issued guidelines for telemedicine services. But lack of awareness and scarcity of literature make telemedicine practice more challenging for both healthcare providers and patients [6-8].

Loeb et al. also examined experience regarding the introduction of telemedicine during the COVID-19 crisis, where the authors estimated that $50 \%$ of the clinical volume was maintained with telemedicine services provided by their hospital. Similarly in the present study, in both groups, the surgeon enquired about surgical findings, post-operative recovery period, degree of pain, and physical examination, which included the motion range testing, any discharge from the operative site, fever, and redness around the wound. During telemedicine follow-up, the surgeon did not feel or even touch the knee, but the surgeon could analyze patients by visual assessment of wound healing, discharge, and swelling around the knee [9-12].

Buvik et al. stated that visual consultations are less impactful when compared to normal consultations, and no significant difference in the number of surgically treated patients was detected across groups $(p=0.60)$ [13]. In an orthopedic randomized controlled trial, Haukipuro et al. discovered that the satisfaction rate of patients was equivalent in the telemedicine and conventional OPD follow-up group [14].

The advantages of orthopedic telemedicine, on the other hand, are not without significant drawbacks, which are linked to a lack of awareness of patients regarding telemedicine choices. As per a survey by J.D. Power (2019), 29\% of patients who never used telemedicine stated about the unavailability of such services while 
37\% lacked awareness regarding telemedicine being given by their healthcare provider [15]. Also, orthopedic surgeons have apprehensions regarding the inability to perform physical examinations, for example, numerous maneuvers like manual motor testing, sensory examination, reflex testing, etc. done during physical examination are impossible to perform via virtual consultations [16]. Moreover, a 2017 survey by the American Orthopaedic Association, revealed that only $20 \%$ of orthopedic surgeons had faith in the usefulness of telemedicine for postoperative follow-up whereas $42 \%$ suggested that majority of their fellows would be disinterested in providing telephonic consultations [17].

In this study, the satisfaction rating among the two groups was statistically insignificant. Mean patient satisfaction scores (on a 10-point scale) were 9.77 in the inpatients visit-based follow-up and 9.79 in telemedicine follow-up. In the present study of post-operative patients, the satisfaction score was $100 \%$, which was comparable to other studies done focused on orthopedics patients.

Couturier et al. (1998) and Aarnio et al. (1999) used video-conference $(\mathrm{n}=15)$ and reported 80\% and 87\% satisfaction rate, respectively [18,19]. Williams et al. (2008) from the United Kingdom used telephone services $(n=598)$ and had a higher satisfaction rate of 93\% [20]. More recently, Buvik et al. (2019) from Norway ( $n=199)$ and Coronado et al. (2020) from the USA reported satisfaction rates of $99 \%$ and $100 \%$, respectively $[13,21]$. The trends signify that the satisfaction rates have increased over the years probably because of the better acceptability of technologies available among both patients and healthcare providers. Similarly, Kumar et al. (2020) from India who used telephone services $(n=450)$ had $92 \%$ of patients satisfied with telemedicine thus emphasizing that telemedicine is being accepted in orthopedic practice in India as well [8].

The role of telemedicine in postoperative care has been emphasized again and again in western literature. Marsh et al. compared one-on-one consultations and postoperative follow-up (at least one year) by telemedicine in 229 patients (118 in telemedicine and 111 in the usual-care group) and suggested telemedicine being a more economical and time-saving option [22]. In addition, Thomas et al. illustrated the essentiality of telemedicine as a method for preoperative education regarding arthroplasty patients and thus helping in better postoperative rehabilitation [23]. Eichler et al., in a randomized controlled study, demonstrated better functional outcomes, reduced pain, and enhanced life quality. Similarly, the present study attempts to evaluate pain score and patient satisfaction score both preoperatively and postoperatively [24].

Limitations

The present study is a preliminary observation study and is limited by the small sample size and detailed questionnaire-based follow-up and lack of knowledge of the educational status of the participants. However, it can be considered as a progressive step toward improving patient outcomes using telemedicine, and therefore larger studies with large sample sizes and longer follow-ups can be carried out for better understanding.

\section{Conclusions}

The improvement and utilization of telemedicine have increased as an impact of the COVID-19 pandemic, which has caused a sudden shift toward the utilization of virtual orthopedic assessments as an important measure. Therefore, with eased guidelines, better cost-effectiveness, and increased awareness among orthopedic surgeons, healthcare providers and patients can improve the quality and efficiency of virtual visits.

\section{Additional Information Disclosures}

Human subjects: Consent was obtained or waived by all participants in this study. Government Medical College, Patiala issued approval TRG.9(310)2020-35217. Animal subjects: All authors have confirmed that this study did not involve animal subjects or tissue. Conflicts of interest: In compliance with the ICMJE uniform disclosure form, all authors declare the following: Payment/services info: All authors have declared that no financial support was received from any organization for the submitted work. Financial relationships: All authors have declared that they have no financial relationships at present or within the previous three years with any organizations that might have an interest in the submitted work. Other relationships: All authors have declared that there are no other relationships or activities that could appear to have influenced the submitted work.

\section{References}

1. Haut ER, Leeds IL, Livingston DH: The effect on trauma care secondary to the COVID-19 pandemic: collateral damage from diversion of resources. Ann Surg. 2020, 272 :e204-7. 10.1097/SLA.0000000000004105

2. Horton R: Offline: don't let COVID-19 divert us completely . Lancet. 2020, 395:1534. 10.1016/S01406736(20)31130-2

3. Tanaka MJ, Oh LS, Martin SD, Berkson EM: Telemedicine in the era of COVID-19: the virtual orthopaedic 
examination. J Bone Joint Surg Am. 2020, 102:e57. 10.2106/JBJS.20.00609

4. Telemedicine practice guidelines: enabling registered medical practitioners to provide healthcare using telemedicine. (2020). Accessed: May 24, 2020: https://www.mohfw.gov.in/pdf/Telemedicine.pdf.

5. Kleiss I, Kortlever J, Karyampudi P, et al.: A comparison of 4 single-question measures of patient satisfaction. J Clin Outcomes Manag. 2020, 27:41-8.

6. Kapoor A, Patil B, Malhi MS, Kalappagol R, Mittal N, Gagan DJ: The practicality of telemedicine in orthopaedics perspectives from a developing nation. JOJ Orthoped Ortho Surg. 2021, 2:98-100. 10.19080/JOJOOS.2021.02.555600

7. Iyengar K, Jain VK, Vaishya R: Pitfalls in telemedicine consultations in the era of COVID 19 and how to avoid them. Diabetes Metab Syndr. 2020, 14:797-9. 10.1016/j.dsx.2020.06.007

8. Kumar S, Kumar A, Kumar M, Kumar A, Arora R, Sehrawat R: Feasibility of telemedicine in maintaining follow-up of orthopaedic patients and their satisfaction: a preliminary study. J Clin Orthop Trauma. 2020, 11:S704-10. 10.1016/j.jcot.2020.07.026

9. Acharya RV, Rai JJ: Evaluation of patient and doctor perception toward the use of telemedicine in Apollo Tele Health Services, India. J Family Med Prim Care. 2016, 5:798-803. 10.4103/2249-4863.201174

10. Loeb AE, Rao SS, Ficke JR, Morris CD, Riley LH 3rd, Levin AS: Departmental experience and lessons learned with accelerated introduction of telemedicine during the COVID-19 crisis. J Am Acad Orthop Surg. 2020, 28:e469-76. 10.5435/JAAOS-D-20-00380

11. Del Rio C, Malani PN: COVID-19-new insights on a rapidly changing epidemic . JAMA. 2020, 323:1339-40. 10.1001/jama.2020.3072

12. Ranney ML, Griffeth V, Jha AK: Critical supply shortages - the need for ventilators and personal protective equipment during the Covid-19 pandemic. N Engl J Med. 2020, 382:e41. 10.1056/NEJMp2006141

13. Buvik A, Bergmo TS, Bugge E, Smaabrekke A, Wilsgaard T, Olsen JA: Cost-effectiveness of telemedicine in remote orthopedic consultations: randomized controlled trial. J Med Internet Res. 2019, 21:e11330. 10.2196/11330

14. Haukipuro K, Ohinmaa A, Winblad I, Linden T, Vuolio S: The feasibility of telemedicine for orthopaedic outpatient clinics--a randomized controlled trial. J Telemed Telecare. 2000, 6:193-8. $10.1258 / 1357633001935347$

15. Telehealth: best consumer healthcare experience you've never tried, says J.D. Power Study . (2020) Accessed: March 24, 2020: https://www.businesswire.com/news/home/20191028005168/en/TelehealthBest-Consumer-Healthcare-Experience-You\%E2\%80\%99v....

16. Angrish S, Sharma M, Bashar MA, Tripathi S, Hossain MM, Bhattacharya S, Singh A: How effective is the virtual primary healthcare centers? An experience from rural India. J Family Med Prim Care. 2020, 9:465-9. 10.4103/jfmpc.jfmpc 112419

17. Odole AC, Ojo OD: A telephone-based physiotherapy intervention for patients with osteoarthritis of the knee. Int J Telerehabil. 2013, 5:11-20. 10.5195/ijt.2013.6125

18. Couturier P, Tyrrell J, Tonetti J, Rhul C, Woodward C, Franco A: Feasibility of orthopaedic teleconsulting in a geriatric rehabilitation service. J Telemed Telecare. 1998, 4:85-7. 10.1258/1357633981931597

19. Aarnio P, Lamminen H, Lepistö J, Alho A: A prospective study of teleconferencing for orthopaedic consultations. J Telemed Telecare. 1999, 5:62-6. 10.1258/1357633991932405

20. Williams M, Amin A, Getgood A, Hallam P, Chojnowski AJ, Chapman PG: Telephone clinic follow-up following carpal tunnel decompression. J Hand Surg Eur Vol. 2008, 33:641-4. 10.1177/1753193408090124.

21. Coronado RA, Sterling EK, Fenster DE, et al.: Cognitive-behavioral-based physical therapy to enhance return to sport after anterior cruciate ligament reconstruction: an open pilot study. Phys Ther Sport. 2020, 42:8290. 10.1016/i.ptsp.2020.01.004

22. Marsh J, Bryant D, MacDonald SJ, et al.: Are patients satisfied with a web-based followup after total joint arthroplasty?. Clin Orthop Relat Res. 2014, 472:1972-81. 10.1007/s11999-014-3514-0

23. Thomas K, Burton D, Withrow L, Adkisson B: Impact of a preoperative education program via interactive telehealth network for rural patients having total joint replacement. Orthop Nurs. 2004, 23:39-44. 10.1097/00006416-200401000-00012

24. Eichler S, Salzwedel A, Rabe S, et al.: The effectiveness of telerehabilitation as a supplement to rehabilitation in patients after total knee or hip replacement: randomized controlled trial. JMIR Rehabil Assist Technol. 2019, 6:e14236. 10.2196/14236 